\title{
The Remodeling of Brand Image of the Time-honored Restaurant Brand of Wuhan based on Emotional Design in the Age of Experience Economy
}

\author{
Jingjing Guo \\ Dept. of Art and Communication \\ Wuhan Polytechnic University \\ Wuhan, China \\ E-mail:cathyinwuhan@163.com
}

\author{
Kije Kwon \\ Dept. of Fine Art and Design \\ Yeungnam University \\ Daegu, Korea \\ E-mail:kije@yu.ac.kr
}

\begin{abstract}
Emotional design theory provides a multi-dimensional, experience-based design concept for the reshaping of the Timehonored brand image. It also has a very important significance in delineating the strong emotional connection of consumers. This thesis starts from the current situation of Wuhan Timehonored restaurant brand image, combines the current trend of experiencing economic environment, and uses the theory of emotional design to put forward some of my own thinking.
\end{abstract}

Keywords: Emotional Design, Time-honored Brand, Brand Image, Experience Economy

\section{INTRODUCTION}

With the development of human science and technology, culture and social economy, commodities have gradually become functional elements of human activities and become human activities. Emotional experience or emotional consumption has gradually developed into an increasingly important form of consumption, serving human emotions. The "experience economy" needed has become another important economic form following the "physical economy" and "service economy." Just as marketing master Philip Kohler wrote in his book "Sales," Starbucks does not sell coffee. Leisure and relaxation; Ferrari sells not a sports car, selling an almost crazy driving pleasure and high-end; Rolex does not sell watches, luxury feeling and self-confidence; Hilton sells not the hotel, is the ultimate comfort and comfort. With the upgrading of the consumer era, there will be more and more commodities that must be given emotional elements in the future.

The city of Wuhan, which has a unique geographical advantage and enjoys the reputation of "center Province". It combines North and South flavors and creates a unique food style. As time went by, Wuhan produced a large number of historical and famous restaurant brands. Wuhan's catering "time-honored" brands are familiar to other long-established brands with its long history and culture. "Nostalgia" is the unique emotional foundation of different brands and other brands, but it only uses the nostalgic mood to temporarily capture the market. But if not following the changes in the market economy environment, the brand's development will be eliminated again as the consumption trend changes. The "time-honored" brand with its own emotional attributes can be said to have met the best era by now.

\section{WUHAN'S “TIME-HONORED” RESTAURANTS BRANDS DEVELOPMENT STAUS}

Wuhan's "time-honored" restaurant brands in addition to old Wuhan people are familiar with the four famous snacks - Laotong City Doupi, Cai Linji dry noodles, the Si Jimei TangBao, Xiao Taoyuan chicken soup, Wu Fangzhai, Cao Xiangtai, Wang Yuxia, Guan Sheng Park and so on. These "time-honored" brand restaurant brands have witnessed the vicissitudes of life for more than a century. They not only witnessed the history of Greater Wuhan, but also contained profound historical and cultural heritage. They are a city and cultural card of Wuhan. Taking old Tongcheng as an example, it was founded in 1929 and is famous for its Doupi. In 1955, after the public-private partnership, Old Tongcheng was renamed "State-owned old Tongcheng Restaurant" and was the first state-owned restaurant in Wuhan. Because of serving with many Chinese and foreign leaders, it became a pride for Wuhan people. In the mid-1980s, there were more than 50 old restaurants in Wuhan and it was an important pillar of the catering industry in Wuhan. Before 1993, these restaurants had always occupied the majority of Wuhan's food and beverage market. Old Tongcheng, Qi Wanshun, and Greater China had all created brilliant sales with annual sales of tens of millions and profits of more than one million. From 1987 to 1989, it was recognized as the peak period of the old Tongcheng City, and its sales ranked first in the same industry in the city.

In the mid-1990s, due to the institutional maladies and geographical location disadvantages, Wuhan's old catering companies embarked on a path of prosperity. On March 14, 2006, the 77-year-old Wuhan Old Tongcheng Restaurant was irreversible and quietly closed. Even though it reopened in 2010, the popularity was far behind. There are also other "time-honored" restaurant brands like the Old Guesthouse Building, the Great Chinese Restaurant, and Wu Fangzhai, which were either barely maintained or acquired. Compared with emerging famous restaurants, these "time-honored "catering companies lacked vitality and strong development momentum, and revitalizing old and famous restaurants are still facing serious challenges. 


\section{THE REMODELING OF THE IMAGE BRAND OF WUHAN'S TIME-HONORED RESTAURANT BRAND}

Based on the status quo of the current catering enterprises, this paper combines the emotional design theory proposed by the famous cognitive psychologist Donald Arthur Norman (1935.12.25-) and puts forward some of my own thinking.

\section{A. Visual Level-Aesthetic Experience}

In the emotional design of Visual Level, consumers focus more on appearance, which is to meet the basic aesthetic requirements of consumers. Recalling the existing status of the existing Wuhan's "time-honored" restaurant brands, some Chinese-Western style designs seem to be out of tune with the "time-honored" temperament. Some brands' features are not prominent enough to attract consumers' attention, and there are also some homogenous designs. As the primary principle of the "time-honored" brand image in emotional design, it is first related to consumers 'sense. The specific operation method may first need to extract the symbolic cultural information unique to the "time-honored" restaurant brands, and then combine and create a modern sense of transmission. The brand image is not only allowing people to feel the warmth of the old brand from the beauty of the new image, but also enables consumers to perceive the brand culture as advancing with the times by contrasting the new image of the old brand. The "time-honored" restaurant brands image should be based on the preservation of traditional culture, make full use of the modern aesthetic characteristics of consumers to adjust the image of the old brand, use the "beauty in time" to awaken the old memories of the old brand, stimulate the emotion, and improve loyalty.

Today's rapid change in consumer culture, so that "beauty" is not just the winning point of the brand, the brand's unique appearance at the same time with the experience based on the brand emotional interaction with consumers has become another breakthrough. In line with the characteristics of the consumer's aesthetic experience, it helps the consumer to memorize the brand's product information, accumulates the brand's emotions, and becomes an important tool to break through the bottleneck. The consumption of modern consumers is no longer merely the commodity itself, but also includes various sensory stimulations and consumption experiences in the process of purchasing consumption. This aesthetic of the purchasing consumption process urges brands to create multi-sensory and multi-dimensional integration for consumers. While innovating experience, we also focus on conveying the meaning and culture represented by the product or brand.

\section{B. Behavior Level-Fun Innovation Experience}

In the behavioral level, consumers are mainly concerned with the fun and efficiency of use. However, regarding fun, most of the "time-honored" brands in Wuhan have never been involved. The "time-honored" restaurant brands in Wuhan have a long history indeed. For most consumers, the "time-honored" brand has built its own brand story in the minds of consumers, but the "aged" phenomenon of the "time-honored" brand is also very serious. The long-term, unmoved attitude of being able to stay in place has created an image of the "aged" in the market. This "old as old" mentality has caused companies to continuously lose their vitality and innovative spirit, which has seriously hindered development of "time-honored" brands.

Also, as "time-honored" brand, "butterfly sewing machine", founded in 1919, has found opportunities in the development of the new era. Butterfly sewing machine nearly as a figure of the era, in the past when the shortage of goods, it was a generic "three big" luxury goods. However, as people's material living standards improved, it gradually disappeared from people's attention. Afterwards, the Shanghai sewing machine factory repositioned the Butterfly brand sewing machine in combination with the current consumer environment. It not only added new technologies to old sewing machines and improved them into modern portable household sewing machines. It also found a breakthrough in the observation of people's life interests now, turning past sewing machines into creative tools.

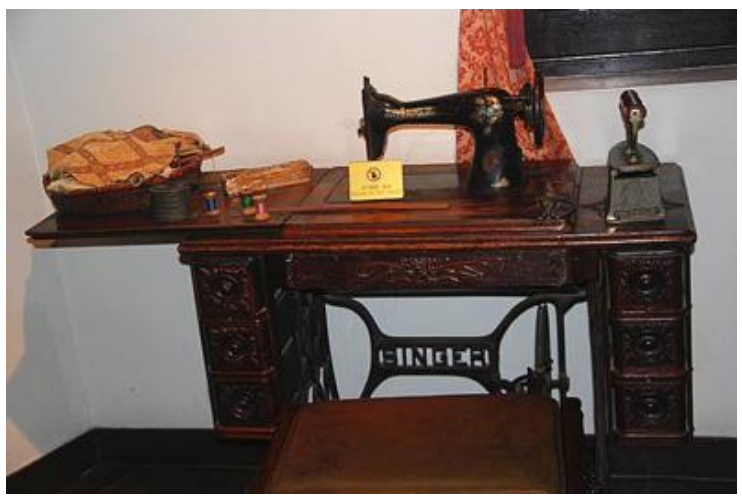

Figure 1. Old style butterfly sewing machine

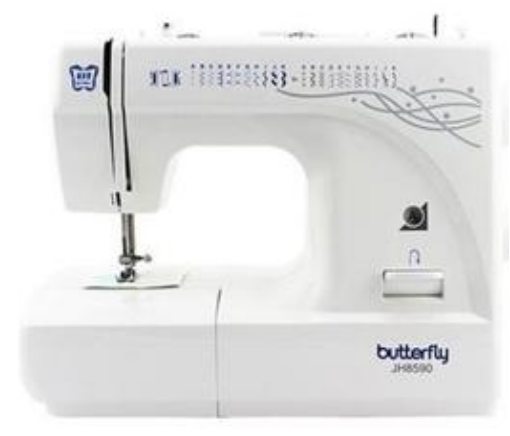

Figure 2. New style sewing sewing machine

They also began to teach people to 'play' sewing machines by training people in the community, streets, schools and other places to use the new experience of 
Butterfly sewing machines from 2010. At the same time, they "open new stores" and transform old-fashioned puresales shops into new shops combining sales and experiences. They not only sell sewing machines, consumers can also experience them in shops and the learning is completely free. After this experience shop opened, it attracted a large number of "butterfly" followers, and sales of sewing machines also gradually increased. This approach reshapes the brand image of the times in the minds of the young generation. The fun and innovative experience has also become a powerful emotional connection between the brand and the modern consumer.

The renewed popularity of the Butterfly brand sewing machine is a revelation to the "time-honored" brands of Wuhan restaurant industry. The time-honored companies need to continue to maintain a new and young way of propagating, which can not only help consumers truly feel the effective process of the "time-honored" brands of food or food production processes, but also allows consumers to reunderstand and redefine the old brand image. Market research consulting firm Mintel's latest "China Consumer Trends in 2018" report also pointed out that young consumers are constantly looking for fun and innovative ways to release daily social pressure is one of the five major trends of consumption in the future. Therefore, the "innovative" and "fun" brand experience will be an effective emotional loyalty point for the continuous transmission of the old brand spirit, and it will also be a powerful internal force to promote consumer thinking.

\section{Reflective Level-Cultural Heritage Experience}

With the globalization of cultural exchanges, under the background of diversification and complexity of consumer groups, what brands want to deliver and communicate with is very limited. Although the "time-honored" brands generally have the attributes of traditional cultural values, they still need to explore the balance and integration of tradition and modernity, and looking at modernity based on cultural continuity. How to make traditional things well integrated into modern times is an urgent problem of the "time-honored" brands.

The Italian designer, Etore Sotsass, said that "protecting the tradition is not simply repeating traditional traditions, not just specific shapes or shapes, but people's feelings of blood and life philosophy." People's feelings about traditions will change with changes in the environment and society. We need to re-examine the concept of cultural continuation, find traditional and modern cultural compatibility points, and carry out positive emotional transmission.

The "time-honored" brands have undergone a century of cultural changes. Facing the rapid changes in modern culture and consumption, the time-honored brands should take a more proactive and positive attitude with their critical attitude, and convert the nutrients in the traditional culture of the time-honored brand into the brand's core values and abilities. The resources for sustainable development have established a cultural heritage with vitality, such as Chen Liji, in 2010, the celebration of the 410th Anniversary and a press conference as the carrier to carry out the "Remodeling Brand Culture Year" campaign. The Guinness Records is a symbol that pushes the "World's longest life pharmaceutical factory" to a new historical height. The modern promotion of brand promotion methods not only enables people to better understand the value connotation of the "time-honored" brand Chen Liji, but also attracts vision from people of the whole world. The development of the company based on the recognition of the customers, provides the driving force for the transformation of the company.

In 2015, Chen Liji issued an industrial strategic development plan and established Chen Liji's "100-year-old Chenpi" secret production workshop. The company also collaborated with a number of scientific research institutions and companies to explore the "private-custom" experiential Chenpi economic model. For different customers with different levels, such as according to different years, set 4 different levels. Among them, the "Chenpi of the 100 Years" is a national cultural relic, which does not participate in market transactions. It is only used in some cultural exhibitions and brand cultural activities. The establishment of the Chen Liji Museum of Chinese Medicine makes the culture of the brand even more lasting. The interactive cultural experience in the museum not only integrates into the era, but also creates memories of every generation. Chen Liji's modern brand promotion has created a multidimensional brand image, penetrated consumers, and providing living cases for the "time-honored" restaurant brands of the Wuhan catering industry.

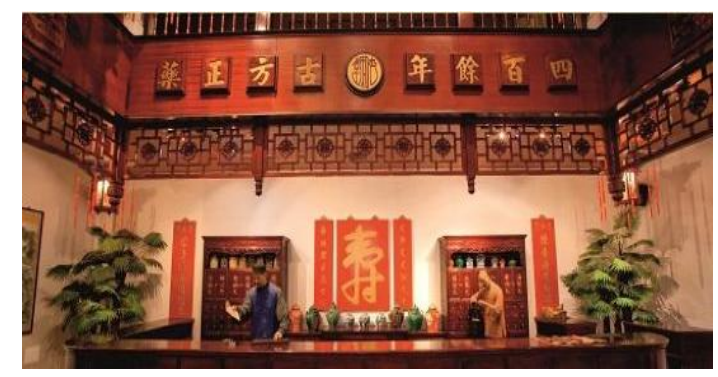

Figure 3. Chen Liji museum of chinese medicine

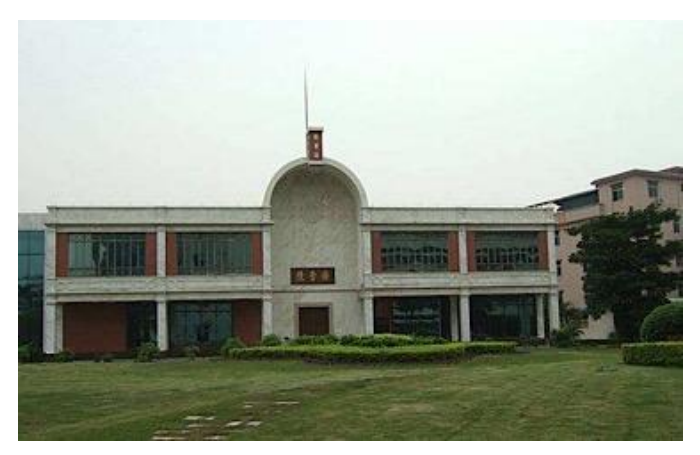

Figure 4. Chen Liji museum of chinese medicine 


\section{CONCLUSIONS}

The Chinese people are historically concerned about food of all. Even if the times are flowing and the technology is changing, the homesickness and memories that arouse the touch of taste are always the deepest feelings in people's hearts. Wuhan "time-honored" brands should seize the opportunity, in the era of experience is creating wealth, experience is creating a brand, experience is creating everything, "Time-honored" brands should comply with changes in economic environment and consumer trends, create "charm products", and create "emotional brand" and "experience marketing." The time-honored brand, with its emotional element, tried its best to impress both the "rational defenders" and the "captives of emotional consumers", making them "really deep in love" with time-honored brands.

\section{REFERENCES}

[1] Zhang Wenqiao, Wu Chenhui. Research on the Reshaping of the Visual Design of the Brand Image of the Old Brand. Popular Literature, 2013, pp. 8-75.

[2] HUANG Weiwei. An Exploration on the Development Tactics of Old-name Catering Trade. Culinary Science Journal of Yangzhou University, 2007(1), pp. 38-41.

[3] Donald A. Norman. Design Psychology 3-- Emotional Design, CITIC Publishing House, pp. 7-22.

[4] Liu Meng, Study on Emotional Design of "Old Brand" Brand Image. Nanjing: Southeast University, 2015.

[5] HE Han. The Study on Brand Strategy of Chinese Traditional Business Enterprises. Tianjin: Tianjin University, 2006.

[6] LI Xiang-wu.The Study of Ethnical Culture on Chinese Historical Restaurant Brands. Beijing: Minzu University of China, 2006.

[7] TANG Zhong-liang.Strategic Problems and Countermea- sures of Enterprise Diversification Strategy in China.Enterprise Economy, 2011(12), pp.15-18.

[8] HOU Dan-dan.The Development of Traditional Media under the Influence of New Media. Brand, 2014(12), pp. 26

[9] LI Yong-quan.Consumer Forest, Brand Regenera- tion[M].Beijing: Life, Reading, New Knowledge Triple Bookstore, 2012

[10] LI Jin.On the Packaging Design Thinking of Brand Rede- sign. Packaging Engineering, 2014, 35(4), pp. 55-56 